Thomassen, L., «Políticas de identidad y ciudadanía: el discurso de Gordon Brown sobre britanidad», REDUR I5,

diciembre 20I7, págs. 85-I09. ISSN i695-078X

\title{
PolítICAS DE IDENTIDAD Y CIUDADANÍA: EL DISCURSO DE GORDON BROWN SOBRE BRITANIDAD
}

\author{
LasSe THOMASSEN \\ Profesor de Ciencias Políticas \\ QUEEN MARY UNIVERSITY OF LONDON
}

SUMARIO: I. Introducción. II. Britanidad como política de identidad. III. ¿Por qué britanidad?. IV. La britanidad de Brown. V. Britanidad, identidad y diferencia. VI. Construyendo la britanidad y lo británico. VII. Resignificando la britanidad. VIII. Poniendo a prueba la britanidad. IX. Conclusión.

RESUMEN: El Brexit ha vuelto a resaltar la importancia de la identidad británica para el futuro del Reino Unido. Este documento examina el discurso del ex primer ministro Gordon Brown sobre britanidad, para, seguidamente, pasar a examinar la forma en que se implementaron estas ideas en la legislación relativa a las pruebas de ciudadanía y la naturalización. El documento identifica una serie de tensiones: entre identidad y diferencia, inclusión y exclusión, particularidad y universalidad, y descriptiva y normativa. A partir de este compromiso crítico con el discurso de Brown y con la legislación, desarrollo la idea de que, capital para la britanidad, debería ser la pregunta «qqué es la britanidad?», y sugiero cómo esto podría abrir un cauce diferente para abordar la identidad británica y la manera en que se transforme en ley.

PALABRAS Clave: britanidad; Gordon Brown; prueba de ciudadanía; exclusión; identidad

ABSTRACT: Brexit has again highlighted the importance of British identity for the future of the UK. This paper examines former Prime Minister Gordon Brown's Britishness discourse, and then goes on to examine the way in which these ideas were implemented in legislation concerning citizenship tests and naturalisation. The paper identifies a number of tensions: between identity and difference, inclusion and exclusion, particularity and universality, and descriptive and normative. From this critical engagement with Brown's discourse and with the legislation, I develop the idea that, central to Britishness, should be the question «what is Britishness?», and I suggest how this might open up a different way of approaching British identity and the way that is transformed into law.

KEYWORDS: britishness; Gordon Brown; citizenship test; exclusion; identity

\section{Introducción}

El Brexit presenta una paradoja: por un lado, los debates previos al referéndum de 2016 у los debates posteriores al mismo hacían referencia a la soberanía de la nación y el pueblo británico, tal como cabría esperar de dicho referéndum; por otro lado, los debates no se referían explícitamente a la naturaleza de la identidad y la ciudadanía británica, sino que estaban más bien relacionados con la inmigración, la naturaleza de la Unión Europea y los 
efectos financieros del Brexit. Esto es aún más paradójico dado que, durante las últimas dos décadas, ha habido una serie de debates políticos y académicos sobre la britanidad y lo que significa ser británico. A veces esos debates han surgido en el contexto de reflexiones sobre la cultura británica de manera más amplia (el Cool Britannia de los primeros años del gobierno de New Labour, por ejemplo); debates sobre el papel y el lugar del Islam en la vida pública británica y, más ampliamente, sobre el futuro del multiculturalismo británico; o debates sobre el futuro de la Unión, especialmente en relación con el nacionalismo escocés. ${ }^{2} \mathrm{Y}$, sin embargo, estas reflexiones sobre la britanidad fueron manifiestamente sometidas al contexto del Brexit. Una excepción a esto es el ex primer ministro Gordon BROWN, quien intentó articular una visión de la britanidad a favor de la permanencia y en contra de la campaña para abandonar la UE. ${ }^{3}$

Esto brinda la oportunidad de regresar a Gordon BROwn y al gobierno del Nuevo Laborismo para examinar sus ideas sobre la identidad y la ciudadanía británica y ver cómo intentaron convertir esas ideas en leyes. A continuación, examinaré el discurso de BROWN sobre britanidad a través de la óptica de la intersección entre, por un lado, la formación de identidades colectivas (aquí: britanidad) y, por otro lado, la cuestión de la inclusión y la exclusión. Esto es importante, porque BROwn y el Nuevo Laborismo presentaron su idea de una identidad británica como inclusiva y contra articulaciones más antiguas y más exclusivas de la identidad británica. La cuestión es, entonces, cómo BROWN y el Nuevo Laborismo negociaron el tema de la inclusión y la exclusión en la manera en que formularon su idea de una identidad británica y en los modos en que la convierten en ley, especialmente en el contexto de la legislación sobre ciudadanía. Tal como explicaré, la britanidad es necesariamente exclusiva porque cualquier identidad, incluso las identidades «inclusivas» y «universales», se articula a través de la particularidad, y porque cualquier discurso de identidad quedará atrapado entre lo descriptivo y lo normativo. ${ }^{4}$

\section{Britanidad como política de identidad}

El discurso sobre britanidad, y las leyes y políticas para institucionalizarlo, es un tipo particular de política de identidad. Por lo general, asociamos la política de identidad con las demandas de los grupos minoritarios frente al estado, por ejemplo, demandas de

Britanidad es la cualidad de ser británico; del mismo modo que anglicidad es la cualidad de ser inglés. Según Real Academia Española, se puede utilizar britanidad o britanicidad, pero los medios españoles normalmente utilicen britanidad.

${ }^{2}$ Acerca de debates de britanidad, véanse los números especiales de The Political Quarterly $78, \mathrm{n}^{\circ}$ I, 2007, eds. Andrew GAMBLE y Tony WRIGHT; y Parliamentary Affairs $6_{3}, \mathrm{n}^{\circ}$ 2, 20IO, eds. Catherine MCGLYNN y Andrew MYCOCK.

Gordon BROwN, «Here's an Inspiring View of Britishness that Can Defeat the Brexit Isolationists», The Guardian Io Mayo 20I6, disponible en https://www.theguardian.com/ commentisfree/2016/may/Io/inspiring-view-britishness-defeat-brexit-isolationists, recuperado por última vez Io Noviembre 2017.

${ }^{4}$ Desarrollo estas ideas en otra dirección en Lasse ThOMASSen, British Multiculturalism and the Politics of Representation, Edinburgh, Edinburgh University Press, 20I7, cap. I. Véase también Lasse ThOMASSEn, «Multiculturalismo y representación: lecciones desde el Reino Unido», Cuadernos Manuel Giménez Abad M6, abril 20I7, págs. 33-4I. 
reconocimiento, derechos especiales o autodeterminación (y generalmente estos grupos son «otros»: distinguidos por su raza, cultura o religión de una población mayoritaria protestante blanca). Tendemos a no utilizar el término política de identidad para el nacionalismo o el patriotismo del estado o de la población mayoritaria, pero con su afirmación de una identidad particular («británica»), la britanidad es también un tipo de política de identidad.

La política de identidad de la britanidad está caracterizada por una tensión básica. La britanidad se supone que es distinta, pero generalmente se articula en torno a valores y principios universales, o casi universales, como la libertad y la equidad. La palabra britanidad está ideada para designar aquello que es común para los británicos, a la vez que crea un espacio para sus diferencias, ya sean nacionales, culturales o ideológicas. Al mismo tiempo, la universalidad e inclusividad de la britanidad es la fuente de reclamaciones en el sentido de que al menos algunas concepciones de la britanidad son demasiado abstractas o «poco consistentes», una protesta que también se levanta contra la idea del patriotismo constitucional. ${ }^{5}$ La denuncia es que la britanidad no es lo suficientemente distintiva como para distinguir a los británicos de otras personas y para integrar las diferencias que existen dentro del Reino Unido. La paradoja de la britanidad es que lo que se supone que distingue a la británica de otras identidades (es decir, de lo que no lo es) es, al mismo tiempo, lo que se supone que incluye las diferencias (nacionales, culturales, etc.). Lo que caracteriza a la britanidad simultáneamente indica lo que es común a los diferentes británicos. Como resultado, estamos obligados a hablar de inmediato y hablar sobre la importancia, el carácter distintivo y lo significativo, de la britanidad. Cuanto más marcada es la britanidad, más fuerza tiene para hacer lo que se supone que debe hacer, es decir, distinguir entre británicos y no británicos. Cuanto más débil es la britanidad, más fuerza tiene para hacer lo que se supone que debe hacer, a saber, incluir diferencias. Dicho de otro modo, para que la britanidad funcione como una identidad común, debe ser a la vez sustancial (y, por lo tanto, exclusiva) y general (y, por lo tanto, inclusiva). Esto suscita los debates sobre la poca o mucha consistencia adecuada de las diferentes formas de liberalismo, por ejemplo, el nacionalismo liberal. ${ }^{6}$ Al igual que la política tradicional de identidad, la britanidad se debate entre la particularidad y la universalidad, y la capacidad de la misma, para funcionar como una identidad común, depende de esta tensión entre la particularidad y la universalidad, y entre la identidad y la diferencia.

Hay otra tensión en la política de identidad de la britanidad. Cuando los grupos hacen llamamientos para que se reconozca su particularidad, generalmente lo hacen en nombre de una identidad que desean quede reflejada en las políticas públicas. Sin embargo,

\footnotetext{
${ }^{5}$ Acerca de esta crítica al dircurso de Gordon BROwn sobre britanidad, véase Bernard CRICK, «The Four Nations: Interrelations», The Political Quarterly, 79, 2008, 7I-9, pág. 77; y Andrew MASON, «Integration, Cohesion and National Identity: Theoretical Reflections on Recent British Policy», British Journal of Political Science, 40, 2010, págs. 857-74, págs. 867 y ss.

${ }^{6}$ Véase el constructivo debate en MASON, «Integration, Cohesion and National Identity». De modo más general, véase Christian JOPPKE, «Immigration and the identity of citizenship: the paradox of universalism», Citizenship Studies, I2, 2008, págs. 533-46. Sobre identidad y diferencia, e inclusión y exclusión, en el contexto legal, véase Martha Minow, Making All the Difference: Inclusion, Exclusion, and American Law, Ithaca, Cornell University Press, I990.
} 
la misma demanda de reconocimiento en sí sugiere que dicha identidad es de alguna manera deficiente, una deficiencia que solo puede repararse a través del reconocimiento. Por lo tanto, el reconocimiento de la identidad particular asume dicha identidad y la constituye al mismo tiempo.

De igual modo con la britanidad: si la britanidad necesita ser promovida a través del discurso sobre britanidad, la educación o las pruebas de ciudadanía, entonces debe ser porque la britanidad no existe por sí misma, sin ayuda, por así decirlo. Ha de ser creada. Además, puede haber diferencias sobre lo que es la britanidad, en cuyo caso el discurso sobre britanidad tiene una dimensión normativa, promoviendo una $\mathrm{u}$ otra forma de britanidad. Con lo cual, el discurso sobre britanidad no es solo descriptivo, ya sea de una esencia ya sea de un hecho sociológico. El discurso sobre britanidad tiene una dimensión performativa (y normativa) donde el discurso sobre britanidad crea la britanidad a la que se refiere. A menudo, esta dimensión performativa se esconde detrás de la dimensión constatativa (y descriptiva) por la cual el discurso sobre britanidad es el reflejo de una esencia o hecho ya existente. Aunque este último tiende a despolitizar la britanidad, la dimensión constatativa no se puede evitar. Con el fin de tener un debate significativo sobre la britanidad, se ha de hacer referencia a algún significado más o menos compartido de britanidad. Esto es así incluso si el significado compartido no es una esencia o un hecho establecido, e incluso si el significado de britanidad se halla en disputa. Sin embargo, la tensión permanece: el discurso sobre britanidad se refiere a la britanidad y, al mismo tiempo, crea aquello a lo que se refiere.

Enfocándome en el discurso de BROwN sobre la britanidad, a continuación, mi objetivo no es criticar su concepción de britanidad como demasiado poco consistente o demasiado marcada. Tampoco se trata de criticar las formas en que a veces es descriptivo y a veces, normativo. Eso es inevitable. En cambio, defenderé una aproximación alternativa a la britanidad, una que asuma la pregunta «¿qué es la britanidad?» como parte de lo que es la britanidad. Al hacer de esta pregunta parte de la britanidad, se ponen de relieve las tensiones que identifico en el discurso sobre britanidad, por lo que nos permite abordar los debates sobre la britanidad de manera diferente. Para mostrar las implicaciones que este cambio de enfoque tiene para la política, hago un repaso en la última sección a las pruebas de ciudadanía introducidas bajo el gobierno del Nuevo Laborismo, las cuales fueron parte de su intento de concretizar la britanidad en la ley.

\section{III. ¿Por qué britanidad?}

Hay tres razones por las cuales Gordon BROwn promueve la britanidad.? Primero, aunque BROWN siempre estuvo preocupado por la descentralización, y especialmente por la devolución de poder a Escocia, la devolución del poder por parte del gobierno laborista a Irlanda del Norte, Escocia y Gales ha atenuado el problema de lo que une las partes

\footnotetext{
${ }^{7}$ Para analizar el discurso de BRown sobre britanidad, principalmente me baso en sus ponencias editadas, así como en alguno de sus libros anteriores. La mayoría de sus ponencias están recogidas en Gordon BRown, Moving Britain Forward: Selected Speeches 1997-2006, ed. Wilf Stevenson, London, Bloomsbury, 2006.
} 
constituyentes del Reino Unido de Gran Bretaña e Irlanda del Norte. ${ }^{8}$ Irlanda del Norte y Gales reciben poca atención de BROWN y su objetivo principal es Escocia, acentuado por el referéndum escocés de independencia en $2014 .{ }^{9}$ La britanidad es una forma de articular a Escocia dentro del Reino Unido y contrarrestar el separatismo del Partido Nacional Escocés (SNP). Entre otras cosas, la britanidad es una forma de convencer a los escoceses de que ser británico no es sinónimo de ser inglés..$^{10}$ La britanidad también está dirigida a Inglaterra, aunque esto siempre está implícito en el discurso de BROWN. Aquí la britanidad es una forma de BROwN para convencer a los ingleses de que no solo son ingleses, sino también, y principalmente, británicos; y una forma de evitar que Inglaterra desarrolle una entidad política separada con una identidad política distinta. ${ }^{\text {II }}$ La clave aquí también es la asimetría descentralizadora reflejada en el asunto West Lothian. Aquí hay una asimetría constitucional porque los diputados que representan a los electores escoceses pueden votar sobre leyes que pertenecen solo a Inglaterra, pero los diputados de los distritos electorales ingleses no pueden hacer lo contrario. Esto se convierte para BROWN en el asunto Kirkcaldy and Cowdenbeath, haciendo referencia al nombre de su distrito electoral escocés: caso insólito donde un Primer Ministro escocés de Gran Bretaña puede votar sobre asuntos pertenecientes a distritos electorales del sur de la frontera anglo-escocesa y que no pertenecen a su propia circunscripción del norte de la frontera. ${ }^{\mathrm{I} 2}$ Por lo tanto, la britanidad es una forma con la que BROWN consigue fortalecer la legitimidad del orden constitucional del Reino Unido. ${ }^{13}$

Una segunda razón para que BROWN promueva la britanidad es el carácter multicultural del Reino Unido contemporáneo, algo que BROWN menciona a menudo y conjuntamente, tal como la inmigración y el terrorismo, algo que lleva a deducir que el problema es el islam (radical). ${ }^{\mathrm{I}}$ Implícitamente, la britanidad se convierte en una forma de hacer que los musulmanes británicos sientan lealtad hacia el Reino Unido y se sientan

\footnotetext{
${ }^{8}$ La terminología no está exenta de problemas. BROwn utiliza británico y britanidad para referirse al Reino Unido de Gran Bretaña e Irlanda del Norte, pero por lo general solo denomina a este último como Gran Bretaña. En este artículo, empleo «UK» como abreviatura para referirme al Reino Unido de Gran Bretaña e Irlanda del Norte.

${ }^{9}$ Véase H. M. Drucker y Gordon Brown, The Politics of Nationalism and Devolution (Longman); Gordon Brown and Robin Cook (eds.), Scotland: The Real Divide. Poverty and Deprivation in Scotland, Edinburgh, Mainstream Publishing, I983; Gordon BRown y Douglas AlEXAnder, New Scotland, New Britain, London, The Smith Institute, I999; Gordon BRown y Douglas AlEXANDER, Stronger Together: The $21^{\text {st }}$ Century case for Scotland and Britain, London, The Fabian Society, 2007; y Gordon BROwN, My Scotland, Our Britain: A Future Worth Sharing, London, Simon \& Schuster, 20I4.

io Brown y AleXAnder, New Scotland, New Britain, cit., pág. 7. Para un anterior - y diferente punto de vista sobre el «separatismo» escocés, véase DRUCKER y BROWN, The Politics of Nationalism and Devolution.

${ }^{\text {II }}$ Sobre esto, véase Simon LEE, Best for Britain? The Politics and Legacy of Gordon Brown, Oxford, Oneworld, 2007, cap. 5 .

${ }^{\mathrm{I} 2}$ LEE, «Gordon BROWN and the "British Way"», cit. 373 y ss.

${ }^{13}$ Ibid., págs. I40-3.

${ }^{14}$ Gordon BRown, «Moving Britain Forward», en Moving Britain Forward: Selected Speeches 19972006, ed. Wilf Stevenson, London, Bloomsbury, 2006, págs. 246-64, en págs. 249 y ss., 26r. Esta asociación entre multiculturalismo, islam y terrorismo fue también realizada por David Cameron. Véase Lasse Thomassen, British Multiculturalism and the Politics of Representation, Edinburgh, Edinburgh University Press, 20I7, págs. I-3, 222-5.
} 
parte de la sociedad del Reino Unido. La idea de BROwn es que, si bien Gran Bretaña es multicultural y multirracial, existen ciertos valores compartidos que trascienden las diferencias. Los valores compartidos conforman una identidad política común reflejada en la ciudadanía, que BROWN considera como un modelo de «contrato» o «acuerdo» mediante el cual los (nuevos) ciudadanos se incorporan a la identidad y a los valores políticos compartidos. ${ }^{15}$

Si bien las dos primeras razones para la britanidad también podrían describirse como una creación de consenso, merece la pena determinar esta construcción de consenso, pero en un sentido más general, como la tercera razón para que BROWN promueva la britanidad. La britanidad es parte de la «nueva Gran Bretaña», una Gran Bretaña postideológica más allá de la «vieja» política de izquierdas y derechas, y una Gran Bretaña donde todos estamos en el mismo barco, compartiendo los mismos valores y objetivos básicos. Esta visión post-ideológica se pone de manifiesto en el hecho de que, para BROWN, las diferencias que debe incluir la britanidad no son diferencias ideológicas sino étnicas y nacionales.

Anteriormente, BROWN hizo muchas referencias a la tradición socialista, pero ahora hace más referencias a pensadores liberales. ${ }^{16}$ La britanidad ocupa el lugar de los valores socialistas, y consiste en tres valores o principios centrales: libertad, responsabilidad y equidad. La libertad comprende tanto «los derechos del individuo protegido contra un estado arbitrario» como el «empoderamiento», es decir, libertad negativa y positiva en los términos de Isaiah Berlin. ${ }^{\text {I7 }}$ La responsabilidad está vinculada a la comunidad, el compromiso cívico y el deber hacia los demás: «las personas no son solo islas individuales de sí mismas, sino ciudadanos en quienes la identidad, la lealtad y, de hecho, un sentido moral determinan el sentido de la responsabilidad». ${ }^{18}$ La responsabilidad es, a su vez, definida a través de la equidad entendida como «la búsqueda de la igualdad de oportunidades para todos».19 Por lo tanto, la libertad es libertad, la responsabilidad es solidaridad y la equidad es igualdad, aunque lo más importante es la igualdad de oportunidades, no el resultado. ${ }^{20}$ La libertad siempre aparece primero con los otros dos

${ }^{15}$ Gordon BRown, «Speech on Managed Migration and Earned Citizenship», 20 Febrero 2008, disponible en http://webarchive.nationalarchives.gov.uk/+/http://www.numberıo.gov.uk/Pager4624, recuperado 22 Julio 20I0; y Gordon BROWN, «Liberty, Responsibility and Fairness», en Moving Britain Forward: Selected Speeches 1997-2006, ed. Wilf Stevenson, London, Bloomsbury, 2006, págs. 27-45, en pág. 3I.

${ }^{16}$ Véase LEE, Best for Britain?, cit., caps. I-2. Véase también el análisis del socialismo en Gordon Brown y Tony Wright, «Introduction», en Gordon BROWN y Tony Wright (eds.), Values, Visions and Voices: An Anthology of Socialism, Edinburgh, Mainstream Publishing, I995, págs. 13-29.

${ }^{17}$ BROwN, «Liberty, Responsibility and Fairness», cit., pág. 32. Isaiah BERLIN, «Two Concepts of Liberty», en Four Essays on Liberty, Oxford, Oxford University Press, I969, págs. II8-72.

${ }^{18}$ BROWN, «Liberty, Responsibility and Fairness», cit., pág. 37.

I9 Ibid., pág. 4I.

${ }^{20}$ Sobre esto, véase Gordon Brown, «Modern Public Services», en Moving Britain Forward: Selected Speeches 1997-2006, ed. Wilf Stevenson, London, Bloomsbury, 2006, págs. I8I-206, en pág. I97. BROWN tiende a utilizar «equidad» en vez de «igualdad», pero véase un anterior uso explícito de «igualdad» en Gordon Brown, «Introduction», en BROwn y Cook (eds.), Scotland, cit., págs. 9-22, en págs. 20-2. 
calificándola y apoyándola, y la libertad es libertad individual, incluso si necesita el apoyo de las comunidades.

BROWN prima cada vez más el mercado sobre el estado y lo relaciona con el desarrollo de habilidades y el potencial humano. ${ }^{21}$ El debate sobre estado frente a mercado es formulado por BROWN, cada vez más, en relación con una distinción entre «viejo» y «nuevo», que es la que de manera importante organiza los puntos de vista de BROWN. El antagonismo entre la izquierda y la derecha sobre los roles del estado y el mercado se caracteriza repetidamente por términos de «dogma» e «ideología» y como «viejo» en oposición a «nuevo» y «moderno». ${ }^{22}$ BROWN hace referencia a los «conflictos desactualizados» y las «divisiones estériles» del pasado, pero estos son, o pueden ser, superados en el presente por «un propósito económico compartido». ${ }^{23}$

El lenguaje de BROWN de «viejo» y «nuevo» es parte del discurso modernizador del Nuevo Laborismo. ${ }^{24}$ El lenguaje «viejo» frente al «nuevo» proporciona una manera de detenerse en el lado correcto de la historia y una forma de luchar contra dos enemigos al mismo tiempo: los conservadores y la izquierda laborista. «Nuevo» y «moderno» son parte de un nuevo consenso más allá de las «dos naciones» del período de THATCHER; ${ }^{25}$ si hay dos naciones, o dos Gran Bretañas, entonces son la vieja y la nueva Gran Bretaña. El nuevo consenso, o la nueva Gran Bretaña, se caracteriza por la «britanidad». De esta manera, los «valores británicos» son parte de un proyecto político para sustituir un nuevo consenso por viejas diferencias sobre el socialismo, el estado frente al mercado, y así sucesivamente. Para BROWN, el propósito compartido y los valores británicos compartidos facilitan «tomar decisiones difíciles sobre prioridades que determinarán nuestro éxito», esto es, el éxito económico del Reino Unido en un mundo globalizado. ${ }^{26}$ Esta es la versión de BROWN de «la unidad política y económica» del Reino Unido, ${ }^{27}$ y se refiere específicamente a las «soluciones británicas» para los desafíos económicos. ${ }^{28}$ En la medida en que el proyecto británico de BROwN tiene éxito en establecer un consenso sobre los objetivos, las «elecciones difíciles» ya no son tan difíciles porque se reducen a elecciones sobre los medios para alcanzar objetivos comunes en lugar de decisiones sobre los objetivos mismos. La britanidad se convierte en un «laborismo de una única nación» contemporáneo.

${ }^{21}$ Por ejemplo, Gordon BRown, «Advancing the Public Interest», en Moving Britain Forward: Selected Speeches 1997-2006, ed. Wilf Stevenson, London, Bloomsbury, 2006, págs. I36-80, en págs. I49 y ss. Véase también LEE, Best for Britain?, cit., cap. I.

${ }^{22}$ BROWN, «Advancing the Public Interest», cit., pág. 146.

${ }^{23}$ BROWN, «Towards a Modern Economy», en Moving Britain Forward: Selected Speeches 1997-2006, ed. Wilf SteVenson, London, Bloomsbury, 2006, págs. 84-135, en pág. IIo. Véase también Gordon BRown, Courage: Eight Portraits, London, Bloomsbury, 2007, págs. I30 y ss.

${ }^{24}$ Norman Fairclough, New Labour, New Language?, London, Routledge, 2000, especialmente págs. I8 y ss. sobre el uso que el Nuevo Laborismo hace del término «nuevo».

${ }^{25}$ Gordon BRown, Where there is Greed...Margaret Thatcher and the Betrayal of Britain's Future, Edinburgh, Mainstream Publishing, 1989, pág. 76.

${ }^{26}$ Gordon BRown, «Britishness», en Moving Britain Forward: Selected Speeches 1997-2006, ed. Wilf Stevenson, London, Bloomsbury, 2006, págs. I-26, en pág. 6. Véase también Brown, «Liberty, Responsibility and Fairness», cit., pág. 3I.

\footnotetext{
${ }^{27}$ Véase DRUCKER y BROWN, The Politics of Nationalism and Devolution, cit., pág. IO2.

${ }^{28}$ Por ejemplo, BROwN, «Towards a Modern Economy», cit., pág. 90.
} 


\section{La britanidad de Brown}

Para Gordon BROwN, la britanidad se refiere a los tres valores libertad, responsabilidad y equidad. Aunque la libertad -el «hilo de oro que recorre la historia británica $»^{29}$ - se menciona primero, es la combinación de los tres valores y la forma en que se han articulado históricamente los que los hacen valores específicamente británicos. ${ }^{30}$ Estos tres valores centrales se detallan en instituciones y valores más concretos, como el sector voluntario y «un asentamiento británico exclusivo» de la relación entre el estado y el mercado y entre los derechos y las responsabilidades. ${ }^{31}$ Además, la britanidad se caracteriza por ser «internacionalista», es decir, por mirar hacia afuera, debido al hecho geográfico de que Gran Bretaña es una isla..$^{32}$ BROWN, a veces, equipara en importancia al valor del internacionalismo con el de la libertad, la responsabilidad y la justicia, pero en otras ocasiones se refiere al mismo como una «calidad».33

La libertad, la responsabilidad y la imparcialidad son valores políticos, y siendo políticos, la britanidad no se basa en la raza, la etnia, la religión, etc. no se basa en un «partido de cricket». ${ }^{34}$ Aquí BROWN hace una distinción entre «un fuerte sentido de patriotismo compartido» y los nacionalismos..$^{35}$ Escribe lo siguiente sobre el patriotismo de la britanidad:

«Esto no es patrioterismo, sino práctico, racional y útil, y, por lo tanto, me atrevería a decir que es una forma de patriotismo esencialmente británica. Patriotismo ... define una nación no por raza o etnia, sino por vernos a todos como parte de un proyecto colectivo del cual todos ganamos y al que todos contribuimos. La sociedad es, como nos han dicho los grandes pensadores, un contrato, incluso un pacto, en el que reconocemos que nuestros destinos están interrelacionados» ${ }^{36}$.

BROwN cree que la britanidad no debe basarse en «identidades exclusivas». ${ }^{37}$ Es posible tener identidades duales o múltiples, por ejemplo, tener una identidad nacional como escocés y al mismo tiempo suscribirse a una identidad global británica. ${ }^{38}$ Esta noción

\footnotetext{
${ }^{29}$ BROwN, «Britishness», cit., pág. I3.

${ }^{30}$ Ibid., págs. I2s.

${ }^{31}$ BRown, «Delivering Local Public Services», en Moving Britain Forward: Selected Speeches 19972006, ed. Wilf STEVEnSON, London, Bloomsbury, 2006, págs. 207-22, en pág. 217.

${ }^{32}$ BROWN, «Britishness», cit., pág. I8. La «mentalidad isleña» viene a significar algo diferente de lo que, por general, significa; esto es, mirar hacia dentro.

${ }^{33}$ BROWN, «Liberty, Responsibility and Fairness», cit., págs. 44 y ss.; y Brown «Moving Britain Forward», cit., pág. 252.

${ }^{34}$ BROwN, «Britishness», cit., págs. 6 y ss.

${ }^{35}$ Gordon BRown, «Introduction», en Matthew D'AnConA (ed.), Being British: The Search for the Values That Bind the Nation, Edinburgh, Mainstream Publishing, 2009, págs. 25-34, en pág. 27.

${ }^{36}$ Brown, «Speech on Managed Migration and Earned Citizenship», cit. Véase también Brown, «Moving Britain Forward» cit.; y BRown, Courage, cit., págs. 34 y ss.

${ }^{37}$ Brown, «Britishness», cit., pág. 6.

${ }^{38}$ Brown y AleXANDer, New Scotland, New Britain, cit., págs. 20, 22. Véase también Brown y AleXANDER, Stronger Together, cit. BROWn también se refiere a esto como «britanidad-plus». Brown, «Introduction»cit., pág. 32.
} 
de la britanidad hace posible tener unidad en un nivel (el nivel de valores políticos) y diversidad en otro nivel, de modo que la unidad política puede ser multicultural o multinacional. ${ }^{39}$ Para BROwN, esta diversidad dentro de la unidad política es positiva, ${ }^{40}$ pero se ha de tener en cuenta que la diversidad es cultural y nacional y se distingue del nivel político en el que debe haber unidad. Crear un espacio para las diferencias culturales y nacionales implica que estas identidades son importantes, pero al mismo tiempo se relativizan con respecto a la identidad política.

La britanidad tiene una dimensión histórica; une pasado y presente. Los valores de la libertad, la responsabilidad y la equidad corren como un hilo conductor en la historia británica, según BROWN, y esta historia se remonta a 2000 años atrás. ${ }^{41}$ Lo que se necesita hoy es «[redescubrir] de nuestra historia los valores compartidos que nos unen». ${ }^{42}$ Estos antiguos valores británicos están esperando que los redescubramos, y la creación de una nueva Gran Bretaña consiste en volver a invocar estos valores. Por lo tanto, la creación performativa de una nueva Gran Bretaña consiste en la reproducción de algo que ya existe. La nueva Gran Bretaña debería ser el reflejo de una antigua Gran Bretaña; lo nuevo se convierte en la continuación legítima de lo viejo.

Esto parecería contradecir la opinión de BROwn de que la «nueva» política se opone a la «vieja» política. Sin embargo, BROWN puede conciliar los dos puntos de vista porque la política «antigua» se presenta como una aberración con su énfasis unilateral ya sea en el estado ya sea en el mercado. En más de una ocasión, BROWN denomina aberraciones a las ideologías y políticas conservadoras, y así el thatcherismo estaba en desacuerdo con los valores británicos más duraderos. «La justicia social no ha sido abandonada por el público, sino que su gobierno la ha hecho callar temporalmente», ${ }^{43}$ escribió entonces. La nueva Gran Bretaña de BROWN es la continuación de algo más antiguo que «viejo», una tradición más auténtica y más británica que se remonta a través de John Stuart MILL y Adam SMITH hasta la Carta Magna y aún más allá. La «nueva» política es una forma de volver a la auténtica pista británica: «Este programa que propongo ... está ... en sintonía con las tradiciones británicas y los valores británicos perdurables. De hecho, este programa de prosperidad y reforma es el medio moderno de aplicar los valores británicos perdurables». ${ }^{44}$

\section{Britanidad, identidad y diferencia}

Para contrarrestar el argumento de que los valores de responsabilidad, equidad y libertad no son particularmente británicos, sino que se comparten con muchos otros

\footnotetext{
${ }^{39}$ Brown y AleXANDER, New Scotland, New Britain, cit., pág. 30.

${ }^{40}$ Ibid., págs. 30 y ss.

${ }^{4 \mathrm{I}}$ BROWN, «Liberty, Responsibility and Fairness», cit., pág. 32.

${ }^{42}$ BROWN, «Britishness», cit., pág. 7.

${ }^{43}$ BROwn, Where there is Greed..., cit., pág. 8.

${ }^{44}$ BRown, «Advancing the Public Interest», cit., pág. I74.
} 
países ${ }^{45}$ Gordon BROwn agrega dos calificadores. Primero, es la combinación y articulación mutua de los tres valores lo que los hacen británicos; y, en segundo lugar, su articulación particular es el resultado de experiencias históricas singulares como británicos. Así pues, existen diferentes interpretaciones de libertad, equidad y responsabilidad, y hay una interpretación específicamente británica de ellas. Esto parecería resolver el problema de cómo se distingue la britanidad de lo que no es británico.

Sin embargo, esto es solo así en un sentido superficial porque no tiene en cuenta los desacuerdos sobre (la interpretación de) los valores entre los británicos, ya sea hoy en día o históricamente. Por ejemplo, desde la perspectiva de la libertad positiva, la libertad negativa puede no aparecer como libertad en absoluto, o como mucho como una libertad muy limitada. Por el contrario, desde la perspectiva de la libertad negativa, la libertad positiva puede aparecer como el opuesto exacto de la libertad. BROWN cree que necesitamos una combinación de libertad positiva y negativa,$^{46}$ pero esto no aborda las diferencias ideológicas sobre la libertad, la equidad y la responsabilidad (y, por supuesto, estas diferencias también existen en otros países).

Los ejemplos históricos de BROWN de la libertad como algo esencialmente británico también muestran que la libertad es, y era, de hecho, un valor impugnado. Usando un ejemplo al que regresa reiteradamente, afirma sobre la abolición de la trata de esclavos y la esclavitud: «Cuando Charles Darwin desafió a Gran Bretaña sobre la esclavitud, fue precisamente porque la esclavitud era una afrenta a los valores nacionales que defendía la libertad». ${ }^{47}$ Sin embargo, la necesidad de «desafiar a Gran Bretaña» sugiere que la libertad de los esclavos no era parte de un consenso nacional, sino todo lo contrario. La nación británica estaba dividida sobre la esclavitud y el significado de la libertad.

BROwN también se apropia de la Guerra de Independencia estadounidense por «la idea británica de la libertad»: «quizás irónicamente, la Guerra de Independencia estadounidense fue combatida por ambos lados «en nombre de la libertad británica». ${ }^{48}$ Sin embargo, si ambas partes lucharon con el mismo nombre, esto sugeriría que el nombre («libertad británica») no puede servir para hacer ninguna distinción consecuente, en este caso entre Estados Unidos y Gran Bretaña. Podríamos hablar de diferentes interpretaciones de la «libertad británica», pero esto solo indicaría cómo la libertad de una persona puede ser la tiranía de otra persona.

Tal como esta exposición aclara, existen diferentes interpretaciones de la libertad, incluso hasta el punto de que esas interpretaciones llegan hasta el final; es decir, no existe un concepto de libertad que luego se interprete de manera diferente, sino que permanece igual en lo básico. Al igual que la equidad y la responsabilidad -y, por extensión, la britanidad-, la libertad es un concepto esencialmente controvertido en el sentido del

${ }^{45}$ CRICK, «The Four Nations», cit., pág. 77; y Mason, «Integration, Cohesion and National Identity», cit., págs. 867 y ss.

${ }^{46}$ BROWN, «Liberty, Responsibility and Fairness», cit., págs. 32, 34.

${ }^{47}$ Ibid., págs. 33 y ss.

${ }^{4}$ Ibid., pág. 33 . 
término de W. B. GALLIE. ${ }^{49}$ Lo que es más, los valores o conceptos no son valores ahistóricos los cuales han sido los mismos desde el comienzo de la historia de la britanidad de BROWN. En cambio, tenemos un historial de estos valores o conceptos, incluidas las luchas sobre si deben definir quiénes somos y sobre lo que significan.

Estas luchas son luchas sobre quiénes son los británicos, es decir, qué tipo de personas con qué tipo de valores son británicos. En resumen, son luchas sobre la britanidad, y la britanidad no es anterior a esas luchas sino se constituyó a través de las mismas. Las diferencias sobre los valores son constitutivas en el sentido de que no se pueden contener dentro de un marco definido por, por ejemplo, la libertad o la britanidad. $\mathrm{O}$, para ser más precisos, aunque puedan ser diferencias dentro de ese marco, son al mismo tiempo diferencias sobre el propio marco. En otras palabras, mientras las diferentes partes en la lucha sobre el significado de la britanidad se refieren a los mismos términos (britanidad, libertad, etc.), el significado de esos términos también es el resultado de las luchas sobre ellos. Como resultado, el valor de la libertad no puede usarse como un terreno común sobre el cual resolver desacuerdos. Argumentar, como BRown, que la libertad puede funcionar como «juez y jurado» para resolver controversias, simplemente empuja las controversias al terreno de la libertad y nuestras diferencias sobre la misma. ${ }^{50}$

El dilema de BROwn sobre la britanidad es que, si la britanidad, entendida en términos de valores de libertad, equidad y responsabilidad, puede integrar las diferencias entre, digamos, socialistas y conservadores, entonces no puede distinguir a Gran Bretaña de ninguna manera significativa. Es decir, cuando es suficientemente inclusiva, carece de distinción. Por el contrario, si la britanidad fuera para distinguir una identidad particular para el Reino Unido, no sería capaz de hacer el trabajo de inclusión e integración, por ejemplo, incluyendo personas británicas con concepciones o conceptos muy diferentes de la libertad. Esta es la tensión básica entre la identidad y la diferencia, y entre la particularidad y la universalidad, que marca la política de identidad de la britanidad.

\section{Construyendo la britanidad y lo británico}

El desacuerdo y la diferencia también amenazan la unidad de la britanidad cuando se trata de los ejemplos históricos de britanidad de BROwN..$^{5 \mathrm{I}}$ Aquí el problema es qué eventos históricos e instituciones son ejemplos de britanidad, y cómo interpretarlos. Un buen ejemplo es la abolición de la trata de esclavos como ejemplo de los valores británicos. BROWN escribe: «recordemos lo que podemos lograr juntos. Hace doscientos años este año fueron los británicos los que se unieron y con la mayor iniciativa popular que jamás se había montado en la historia de nuestro país puso fin a la trata de esclavos». ${ }^{52}$ Sea o no la

${ }^{49}$ W. B. GalliE, «Essentially Contested Concepts», Proceedings of the Aristotelian Society, 56, I956, págs. I68-98.

${ }^{50}$ BROwN, «Liberty, Responsibility and Fairness», cit., pág. 33.

${ }^{51}$ Sobre la historia de la britanidad, véase Linda CoLLEY, Britons: Forging the Nation 1707-1837, Ed. rev., New Haven, Yale University Press, 2009, que es un punto de referencia frecuente para BROwN.

$5^{2}$ Gordon Brown, «Speech to the I39th Congress of the TUC», Io Septiembre 2007, disponible en http://news.bbc.co.uk/2/hi/uk_news/politics/69875I5.stm, recuperado 22 Julio 20IO. Cf. BROWN, 
iniciativa el (único) motivo para que el Parlamento apruebe la ley de comercio de esclavos, dicha ley solo prohíbe la trata de esclavos y no la esclavitud en sí misma. Más importante aún, el hecho mismo de que una iniciativa era necesaria muestra que no hubo acuerdo entre los británicos y los parlamentarios para que se aboliera la trata de esclavos. La historia de BROwN del Reino Unido ignora convenientemente el hecho de que había gente británica que estaba muy a favor de la trata de esclavos y pensaba que abolirla sería perjudicial para los intereses británicos. Hace caso omiso de que la lucha para acabar con el tráfico de esclavos fue precisamente eso: una lucha política que también tuvo lugar dentro de la sociedad británica, entre diferentes ciudadanos británicos que hablaron en nombre de Gran Bretaña. Cuando BRown escribe que «los británicos ... se unieron» no es correcto porque algunos británicos se unieron contra otros británicos.

En términos más generales, BROWN ignora las históricas luchas sociopolíticas que han convertido al Reino Unido en lo que es hoy. Esto es así especialmente cuando se trata del estado de bienestar y las relaciones industriales. Aquí encontramos una doble estrategia en los textos de Brown. Por un lado, usa la distinción entre «viejo» y «nuevo» para relegar las luchas ideológicas al pasado. Por otro lado, los perdedores en esas luchas ideológicas -es decir, aquellos que no lucharon por la justicia social- están ausentes en el relato de BROWN sobre el Reino Unido. Por ejemplo, BROWn escribe que «tanto la izquierda como la derecha a lo largo de los siglos» se han comprometido con el «juego limpio», es decir, la igualdad y la justicia social, y esto incluye «la clase media victoriana y los socialistas y sindicatos cristianos». ${ }^{53}$ Este relato histórico pasa por alto las diferencias entre estos electores en sus interpretaciones de lo que significaba la justicia social y cómo debería ponderarse con otros valores (por ejemplo, las diferencias entre las clases medias victorianas y los sindicatos). E incluso si estos distritos electorales hubieran podido luchar durante un tiempo codo con codo, todavía había diferencias importantes entre ellos, y esto ni siquiera tiene en cuenta las opiniones de aquellos contra los que lucharon, -ellos precisamente «lucharon», según las propias palabras de BROWN. ${ }^{54}$

La historia de BROWN del Reino Unido ignora la importancia de las divisiones que han caracterizado al Reino Unido en el pasado y algunas de las cuales todavía lo caracterizan en la actualidad. Escribe el consenso de nuevo en la historia al eliminar de la misma a aquellos que estaban en contra de la abolición de la esclavitud y la justicia social. Sólo de esta manera, por ejemplo, la abolición de la trata de esclavos puede ser asumida como inequívocamente británica y la trata de esclavos puede ser excluida como inequívocamente no británica. BROWN mismo reconoce que su relato de britanidad en su historia del Reino Unido es solo una posible explicación entre varias otras legítimas: «muchos elegirían o enfatizarían las cualidades de los británicos de una manera diferente a

«Liberty, Responsibility and Fairness», cit., págs. 33 y ss.; y Gordon Brown, Britain's Everyday Heroes: The making of the Good Society, Edinburgh, Mainstream Publishing, 2007, págs. 65, I25.

${ }^{53}$ BROwN, «Britishness», cit., pág. I6.

${ }^{54}$ Ibid. Para una crítica similar hacia BROWN olvidando el papel del conflicto histórico, véase Audrey OSLER, «Patriotism, multiculturalism and belonging: political discourse and the teaching of history», Educational Review, 6I, 2009, págs. 85-100. 
mí».55 Él enfatiza que su historia de Gran Bretaña es selectiva ya que consiste en «lo mejor de nuestra historia». ${ }^{56}$ Pero esta calificación simplemente reproduce el problema de quién debe hablar en nombre de Gran Bretaña y la britanidad. Si la britanidad de BROwN es solo una entre muchas, ¿cómo puede integrar a los diferentes puntos de vista sobre la britanidad? Si la britanidad debe ser una expresión de «lo mejor de nuestra historia», esto solo traslada los desacuerdos sobre lo que pertenece a «nuestra historia» a lo que es «lo mejor» de esa historia. Todavía tenemos que preguntar la historia de quién.

BROWN olvida el hecho de que la historia británica es también la lucha por lo que significa ser británico y, en consecuencia, lo que la hace historia británica: lo que la hace nuestra y cómo los británicos se convierten en británicos. ${ }^{57}$ Su historia del Reino Unido no es meramente un reflejo constatativo y descriptivo de una historia no disputada y sin problemas. La selección e interpretación de ejemplos históricos particulares como británicos hace que la historia sea una entre otras posibles historias. Así, la historia de BROWN tiene una dimensión performativa y normativa que interpreta un «nosotros» británico particular, una historia particular como «nuestro» y ejemplos históricos particulares como pertenecientes a dicha historia.

La britanidad no «es» algo esencial o natural. Lo que «es» es el resultado de continuas luchas sobre la britanidad, no algo que precede a esas luchas. Si la unidad de la britanidad no existe naturalmente (por ejemplo, para verse reflejada en las instituciones), entonces debe crearse esta unidad. Ya he mencionado un aspecto de esto: la dimensión performativa y normativa del discurso sobre britanidad. Otro aspecto de esto es que la unidad de la britanidad solo puede ser constituida a través de una relación de diferencia. Dada la dimensión performativa de la britanidad, su unidad no puede consistir en la identidad entre el concepto de britanidad y alguna esencia o realidad subyacente. La unidad de la britanidad se establece mediante una distinción entre británicos y no británicos, que a su vez se basa en distinciones que ponen la abolición de la trata de esclavos, la libertad (estilo británico) y la justicia social del lado británico y sus negaciones en el lado de no británicos. Sin embargo, como he intentado exponer arriba, esta es una empresa ambivalente. Lo que distingue a británicos de no británicos es muy poco consistente (porque algunos presuntamente no británicos suscriben la libertad británica, por ejemplo) o demasiado marcada (porque algunos supuestamente británicos no suscriben los valores británicos o no apoyaron la abolición de la trata de esclavos).

La britanidad de BROwN sigue siendo incapaz de suprimir las diferencias históricas y contemporáneas sobre la libertad, la justicia social, la trata de esclavos, etc., porque esas diferencias también se refieren a la definición de britanidad. En la siguiente sección, sugeriré que, por esta razón, deberíamos convertir a la pregunta «¿qué es la britanidad?» en

\footnotetext{
${ }^{55}$ BROwn, «Britishness», cit., pág. 18.

${ }^{56}$ BROWN, «Liberty, Responsibility and Fairness», cit., pág. 3I.

${ }^{57}$ La relación entre britanidad y lo británico nunca está clara: ¿la britanidad describe lo que los británicos tienen en común? ¿O la britanidad constituye a los británicos como un grupo? En el primer caso, la britanidad simplemente explicaría lo que los británicos ya tienen en común, ya sea dicha comunidad derivada o bien de una esencia compartida o bien del hecho de vivir dentro de un espacio geográfico determinado («británico»). En el segundo caso, los británicos no preexistirían a la britanidad, sino que se constituirían como un grupo a través del discurso de britanidad.
} 
una parte de la britanidad. Aunque tal movimiento no resolverá las tensiones en la noción de britanidad de BROWN, traerá estas tensiones a un primer plano de modo que nos permita abordarlas de una manera más fructífera.

\section{Resignificando la britanidad}

El discurso sobre britanidad de BROWN tiene una dimensión tanto constatativa como performativa, aunque la primera suele tener prioridad sobre la segunda. Tomemos, por ejemplo, la siguiente cita: «más allá del campo de batalla en cuestiones individuales, existe algo en común; es el reconocimiento de la importancia y la necesidad de celebrar y consolidar un carácter británico definido por valores compartidos». ${ }^{58}$ La britanidad existe para reflejarse y celebrarse en un discurso y una política oficiales, pero también debe celebrarse para afianzarla. La necesidad de afianzar la britanidad sugiere que ésta falta, ya sea parcial o totalmente, en cuyo caso no puede reflejarse simplemente como un hecho. El discurso de BROWN sobre britanidad es constatativo cuando afirma reproducir un carácter británico ya existente para ser (re)descubierto y performativo cuando se trata de producir esta britanidad como algo a lo que se aspira. El discurso sobre la britanidad funciona mejor si la dimensión performativa está oculta detrás de la constatativa. Si la britanidad aparece como si fuera un hecho o un reflejo de un hecho, entonces es más fácil afirmar que no es polémica y crear un consenso en torno a ella.

Podemos concebir la constitución performativa de la britanidad como un proceso de resignificación. ${ }^{59}$ Los discursos sobre britanidad, incluido el de Gordon BROWN, son resignificaciones performativas de la britanidad, tanto en su conjunto como en sus supuestas partes (valores, eventos, instituciones, etc.). El proceso de resignificación tiene una dimensión constatativa y performativa. Parte de los discursos existentes y los elementos discursivos, es decir, de las concepciones existentes de britanidad. Es precisamente un proceso de resignificación. Pero el proceso de resignificación es constitutivo de lo que se resignifica: la britanidad no se da antes del proceso, sino que se constituye a través de él. Las resignificaciones no deben entenderse como significados diferentes de algo que permanece igual, independientemente de esas resignificaciones. Si bien el proceso nunca está completamente abierto, los límites son contingentes. La resignificación de la britanidad siempre estará limitada por el terreno discursivo existente y por las desigualdades entre los agentes en ese terreno, pero, dicho esto, en principio, la britanidad puede significar cualquier cosa.

En algunas ocasiones, BROWN mismo se refiere a la britanidad como una cuestión de resignificación, si bien no en esos términos. Sugiere que deberíamos resignificar la bandera del Reino Unido (la Union Jack) como un signo de la unidad y tolerancia de Gran

${ }^{8}$ BROWN, «Britishness», cit., pág. II. Igualmente, en Gordon BROWN y Jack STRAW, The Governance of Britain, London: The Stationery Office, 2007, págs. I80-203.

59 Judith BUTLER y Ernesto LAClAU, «The uses of equality», en Laclau: A Critical Reader, eds. Simon CRITCHLEY y Oliver MARCHART, London, Routledge, 2004, págs. 329-44. 
Bretaña. $^{60}$ Tal resignificación solo es posible en la medida en que, por ejemplo, el Partido Nacional Británico (BNP) y el UKIP no hayan podido monopolizar la significación de la bandera. El proceso de resignificación y reapropiación de la bandera solo es posible porque el proceso de significación y apropiación es siempre incompleto. La resignificación es posible siempre que el significado de la bandera no sea apropiado en el sentido de esencial o apropiado en el sentido de pertenencia a un propietario que pueda controlar su significado. Esto se extiende a la britanidad: se debe a que la britanidad no es apropiada en ninguno de estos dos sentidos en los que puede ser resignificada, no tiene esencia, y nadie puede fijar su significado de una vez por todas.

Sin embargo, BROwN rechaza esta conclusión más radical al escribir que «deberíamos afirmar que la bandera del Reino Unido (la Union Jack) es, por definición, una bandera de tolerancia e inclusión». ${ }^{6}$ La dimensión performativa de la resignificación de la bandera de Reino Unido (la Union Jack) solo aparece al servicio de una verdad constatativa, a saber, que la bandera «por definición» significa tolerancia e inclusión. Aquí se contrasta un significado verdadero y auténtico de la bandera -y de britanidad- con el significado contingente de la bandera.

Si aceptamos el argumento de BROWN, podríamos criticar una resignificación particular de la bandera comparándola con el significado esencial de la bandera. Del mismo modo, si ignoramos la dimensión performativa de la resignificación de los ejemplos históricos de britanidad, podríamos criticar esos ejemplos sobre la base del carácter británico que se dice que reflejan (¿la abolición de la trata de esclavos es realmente un buen ejemplo de britanidad?). En contraste, el reconocimiento de la dimensión performativa de los ejemplos nos permitiría ver que la relación entre el ejemplo y lo que ejemplifica no es unilateral. No tenemos primero britanidad y luego ejemplos de ello. Aunque los ejemplos deben pretender reflejar algo más general (britanidad), la selección e interpretación de los ejemplos también ayudan a constituir lo que ejemplifican (es decir, britanidad). ${ }^{62}$ La britanidad no «es» algo en sí misma (esencialmente, naturalmente), sino solo a través de nuestras representaciones de ella, entre otras cosas a través de los ejemplos que elegimos para representarla.

Por lo tanto, podemos debatir si la abolición de la trata de esclavos es un buen ejemplo de los valores británicos, pero este debate no es independiente del debate sobre qué es la britanidad. El debate sobre la ejemplaridad del ejemplo no puede decidirse comparando el ejemplo con lo que se supone ejemplifica porque este último no es independiente del primero. El ejemplo no se puede reducir a un reflejo constatativo de lo que se supone que debe ejemplificar; también tiene una dimensión performativa por la que constituye lo que se ejemplifica en el curso de sostener reflejarlo.

${ }^{60}$ BROwn, «Moving Britain Forward», cit., pág. 262. Del mismo modo, BROwn y STRAw, The Governance of Britain, pág. 58. La bandera de San Jorge se ha sometido a un proceso de resignificación donde ha perdido sus connotaciones anteriores de racismo y extrema derecha; esto ha sucedido a través de su asociación con el equipo de fútbol de Inglaterra en particular.

${ }^{61}$ BROWN, «Moving Britain Forward», cit., pág. 262.

${ }^{62}$ Para esta comprensión del ejemplo, véase Michael B. NAAS, «Introduction: For Example», en Jacques DeRrIDA, The Other Heading: Reflections on Today's Europe, trads. Pascale-Anne Brault y Michael B. Naas, Bloomington, Indiana University Press, I992, págs. vii-lix. 
Pensar en los ejemplos de britanidad de esta manera abre el camino para un debate sobre la britanidad en donde el énfasis radica menos en la verdad y hacerlo bien y más en la resignificación de britanidad. Podríamos, por ejemplo, querer apropiarnos de la abolición de la trata de esclavos y la guerra de independencia de los Estados Unidos por la britanidad, como lo hace BROWN. Y podríamos rechazar su reapropiación del pasado imperialista británico y en su lugar alinear la britanidad con los movimientos independentistas que luchan contra el imperio y el colonialismo. ${ }^{63}$

Ver la britanidad en términos de resignificación también nos ofrece una manera de responder a aquellos críticos de BROWN que argumentan que sus ejemplos de britanidad son de hecho ingleses. Por ejemplo, Simon LEE escribe: «El elemento y defecto más curioso en el Modo Británico de BROWN es la medida en que solo puede sostenerse recurriendo a ejemplos de historia inglesa o escritos específicamente sobre Inglaterra y lo inglés, y reinventándolos como si tratasen sobre Gran Bretaña y los británicos». ${ }^{64}$ LEE califica el uso que hace BROwN de los eventos ingleses y las referencias literarias a Inglaterra como «citas erróneas y tergiversaciones» porque BROWN las usa para ejemplificar la britanidad. ${ }^{65}$

Como respuesta, se puede preguntar, primero, ¿aparte de lo inglés (o escocés, galés y norirlandés) qué otros serían ejemplos de britanidad? Después de todo, se supone que son las partes constitutivas de Gran Bretaña. En segundo lugar, la crítica de LEE a BROwN parece suponer que lo inglés y lo británico son identidades exclusivas (y que el inglés, el escocés, el galés y el norirlandés también son identidades exclusivas). Existen necesariamente diferencias entre inglés y británico, porque los británicos comprenden más de lo que es inglés, y porque se podría decir que los dos funcionan en diferentes niveles, con británicos a nivel político e inglés a nivel nacional. Sin embargo, se supone que Inglaterra también forma parte de Gran Bretaña, por lo que la relación entre ellos no se puede reducir a una diferencia, y mucho menos exclusión mutua. En tercer lugar, la crítica de LEE a BROWN omite la dimensión performativa por la cual un evento o referencia literaria puede ser «inglés», pero puede ser resignificado como «británico», mientras continúa siendo ambos.

Mientras LEE denuncia que BROWN está «reinventando» sus ejemplos ingleses como ejemplos británicos, debe quedar claro que cualquier uso de ejemplos es

${ }^{63}$ Gordon BROWN en «"No UK apology" for colonial past», I5 enero 2005, disponible en http://news.bbc.co.uk/2/hi/uk_news/politics/4I76805.stm, recuperado 22 Julio 20IO. Véase también Andrew MYCOCK, «British Citizenship and the Legacy of Empires», Parliamentary Affairs, 63, 20IO, págs. 339-55. En un momento dado, BROWN reconoce este problema cuando escribe que «no debemos olvidar los abusos, la discriminación, las injusticias cometidas; y sería un error glorificar o distorsionar el pasado, particularmente para mantener una determinada visión del presente». BROwn, Moving Britain Forward, cit., pág. 33; también pág. I8.

${ }^{64}$ LeE, Best for Britain?, cit., pág. I45; véase también ibid., págs. I54 y ss. Para una crítica similar, véase CRICK, «The Four Nations», cit., 77. Se podría argumentar que los ingleses, incluido LEE, deberían estar contentos de que BRown trate de pasar inglés como británico, y que sea Inglaterra quien defina lo que es Gran Bretaña. De hecho, a menudo se hace referencia a Gran Bretaña como Inglaterra, y británico como inglés, tanto por los extranjeros como por los propios ingleses, y muchas veces la gente tiene en mente Inglaterra incluso cuando usan la palabra Gran Bretaña.

${ }^{65}$ LEE, Best for Britain?, cit., pág. I47. 
reinventivo. ${ }^{66}$ De esto trata el discurso sobre britanidad: reinventar, resignificar, eventos históricos, contemporáneos, instituciones y valores. Eso se puede describir, como LEE lo hace, como «tergiversación», pero no es una tergiversación de, por ejemplo, un original verdaderamente inglés; todo lo que tenemos son significados diferentes y contingentes de anglicidad, britanidad, etc. En el análisis final, el propio LEE reconoce implícitamente el carácter performativo de la britanidad y la anglicidad cuando, al final de su crítica a BROWN, escribe:

«Sería posible construir una política alternativa y un concepto inclusivo de ciudadanía basado en el "hilo de oro de la libertad" de Brown, los "valores centrales democráticos de libertad, equidad, tolerancia y pluralidad" de [Jack] Straw, y el linaje histórico y las citas literarias que han sido promovidas para fundamentar el Modo Británico. Sin embargo, esa historia y literatura en particular han dado una expresión concreta a la posibilidad de un "Modo Inglés"» ${ }^{67}$.

Es posible «construir» la anglicidad con los mismos elementos que BROWN usa para construir la britanidad porque esos elementos no son esencialmente ingleses o británicos, y porque no hay nada esencial acerca de la anglicidad y la britanidad.

Los debates sobre la britanidad no deberían preocuparnos por encontrar la verdad sobre la britanidad; en cambio, deberían ser una lucha sobre cómo resignificar la britanidad. La pregunta «¿qué es la britanidad?» debería ser parte de la britanidad. Esto no es una llamada a una mayor vaguedad o una noción más abstracta de britanidad; más bien, es una forma de resaltar el carácter paradójico del discurso sobre britanidad. La propuesta no resuelve las paradojas de la política identitaria de la britanidad. No afirmo que la pregunta «¿qué es la britanidad?» exprese la esencia de britanidad; a lo sumo es una especie de esencia estratégica. ${ }^{68}$ Tampoco es una definición neutral de britanidad o un metanivel desde donde debatir diferentes ideas de britanidad. La propuesta es en sí misma una definición, o resignificación, de la britanidad entre otras. Sin embargo, también es una forma de institucionalizar un proceso continuo de resignificación. Ese proceso solo está limitado de dos maneras. Está limitado, primero, por los límites contingentes que surgen de la disponibilidad, o no, de los recursos discursivos particulares y del poder relativo de los agentes comprometidos en la resignificación de la britanidad. En segundo lugar, hay un límite (estratégicamente) esencial para la resignificación: la pregunta «¿qué es la britanidad?» no puede resignificarse fuera de la britanidad.

La inclusión de la pregunta «¿qué es la britanidad?» tiene efectos dislocadores, y el resultado es paradójico: tenemos un debate sobre britanidad donde el foco y la base del debate («britanidad») no están fijados, sino que son cuestionados, -o, en la medida en que están fijados, son solo provisionales. Mi propuesta no resuelve la tensión relacionada con la

${ }^{66}$ Ibid., pág. I45. LEE también escribe: «El Modo británico depende ... de reinventar las Inglaterras literarias como si de Gran Bretaña y britanidad se tratase.» Ibid., pág. I46. Contra LEE, el objetivo debe ser resaltar el carácter contingente del «como si», en lugar de rechazarlo como un error. La reinvención es otra forma de pensar sobre la resignificación. Jacques DERRIDA, «Inventions of the Other», en Psyche: Inventions of the Other. Vol. 1, ed. Peggy Kamuf y Elizabeth RotTEnBERG, trads. Catherine Porter, Stanford: Stanford University Press, 2008, págs. I-47, en págs. 6, 39, 45 y ss.

\footnotetext{
${ }^{67}$ LEE, Best for Britain?, cit., pág. I55.

${ }^{68}$ Diana Fuss, Essentially Speaking: Feminism, Nature and Difference, London: Routledge, I989.
} 
doble estructura constatativa/performativa de la britanidad, pero pone esta doble estructura en el centro del proceso de resignificación que surge de la pregunta «¿qué es la britanidad?». Tampoco mi propuesta resuelve la tensión de la diferencia, pero implica que vemos la diferencia de la britanidad como una negociación provisional de identidad/diferencia, inclusión/exclusión y universalidad/particularidad. En el análisis final, lo que distingue a la britanidad y lo que integra las diferencias dentro de la misma, es solo la pregunta «¿qué es la britanidad?», cualesquiera que sean las respuestas (provisionales) a esa pregunta.

\section{Poniendo a prueba la britanidad}

¿Qué podría significar en la práctica incluir la pregunta «¿qué es la britanidad?» en la definición de britanidad? ¿Y en qué medida es practicable? Para responder estas preguntas, examinaré la prueba para obtención de la ciudadanía británica. ${ }^{69}$ Esto parece ser un caso difícil porque una prueba implica una fuerte dimensión de constatación. En el caso de la prueba para la obtención de la ciudadanía británica, es precisamente una cuestión a comprobar si el solicitante tiene «suficiente conocimiento» sobre la vida en el Reino Unido para convertirse en ciudadano británico. ${ }^{70}$ Una prueba, y especialmente una prueba de tipo test, como es la prueba para obtener la ciudadanía británica, asume que puede responder correcta o incorrectamente, sin dejar espacio para cuestionar el contenido de la prueba.

La prueba de ciudadanía se introdujo bajo el gobierno del Nuevo Laborismo y el proceso de convertirse en ciudadano británico también implica una ceremonia de ciudadanía con un juramento y una promesa. ${ }^{\text {II }} \mathrm{Si}$ bien Gordon BROWN fue determinante en la introducción de las pruebas, de ninguna manera fue el único ministro de gobierno involucrado, y parece ser que hubo un consenso entre los ministros relevantes sobre la motivación para la introducción de las pruebas de ciudadanía. En un «Discurso sobre migración administrada y ciudadanía ganada», BROwn dice que, junto con las políticas para lidiar con la inmigración ilegal, las políticas de migración administrada «constituyen una declaración fundamental sobre lo que esperamos de aquellos que aspiran a la ciudadanía británica y cómo tiene la intención de fortalecer la idea de lo que significa ser británico». ${ }^{72}$

${ }^{69}$ Para una introducción crítica, véase Thom BROOKS, Becoming British: UK Citizenship Examined, London, Biteback Publishing, 20I6. A continuación, me centro en la ciudadanía y las pruebas de ciudadanía durante los años del Nuevo Laborismo. Han cambiado bajo los siguientes gobiernos Conservador-Liberal-Demócrata y Conservador, pero los principios básicos siguen siendo los mismos.

${ }^{70}$ Home OfFICE, The New and the Old: The Report of the «Life in the United Kingdom» Advisory Group, London, Home Office, 2003 , pág. 3.

${ }^{7}$ Para detalles completos sobre las diferentes vías para la naturalización, véase Nationality, Immigration and Asylum Act 2002 (Part I), disponible en http://www.legislation.gov.uk/ukpga/2002/ 4I/contents; y Borders, Citizenship and Immigration Act 2009 (Part 2), disponible en http://www.legislation.gov.uk/ukpga/2009/II/contents.

${ }^{72}$ Agrega en el mismo lugar que la política de migración gestionada «refleja el valor que otorgamos a la ciudadanía británica y la necesidad urgente de tener clara nuestra identidad nacional colectiva y nuestro objetivo común». Véase también BROWN, «Speech to the 139 th Congress of the TUC», cit.. 
De manera similar en los informes y los materiales que acompañan a la prueba, por ejemplo en The Path to Citizenship: «En todo el gobierno estamos introduciendo reformas para fortalecer nuestros valores compartidos y nuestra ciudadanía. El propósito de este documento es establecer cómo la reforma del camino de un recién llegado a la ciudadanía o la residencia permanente puede contribuir a este programa». ${ }^{73}$ Aquí no estoy interesado en los detalles de cómo se diseñó la prueba de ciudadanía (qué discursos llevaron a qué documentos y a qué leyes, etc.). En cambio, quiero examinar la visión de la britanidad reflejado en los informes que forman la base para la introducción de la prueba, en los materiales oficiales que acompañan a la prueba y en la prueba misma.

Las nuevas políticas alientan a los inmigrantes a solicitar la ciudadanía, es decir, a convertirse en británicos; y el proceso es relativamente simple y la ciudadanía relativamente fácil de obtener en comparación con otros países. Al mismo tiempo, las nuevas políticas aumentan la diferencia (en derechos) entre ciudadanos y no ciudadanos, y así entre británicos y no británicos. ${ }^{74}$ Todos pueden convertirse en ciudadanos británicos, y la categoría de británicos está, en principio, abierta a todos, pero se supone que la ciudadanía (y la prueba y la ceremonia) distingue quién es británico y quién no es británico. Las reglas de naturalización y la prueba de ciudadanía están destinadas a hacer que la ciudadanía sea tanto más inclusiva y como más exclusiva también, lo que debería traer a la mente la paradoja de la diferencia examinada anteriormente en el contexto del discurso de BROWN sobre britanidad.

La prueba de ciudadanía consiste en veinticuatro preguntas inéditas de tipo test. Además, la naturalización incluye un requisito de lengua inglesa, así como también requisitos sobre residencia y antecedentes penales, pero a continuación, solo me intereso en la prueba en sí. Hay dos pequeñas guías sobre cómo prepararse y hacer la prueba, así como una guía más grande sobre la naturalización que también incluye información sobre las pruebas. ${ }^{75}$ El libro Life in the United Kingdom, publicado en 2004, y en 2007 en una edición revisada, está destinado a ayudar a quienes se preparan para la prueba de ciudadanía y contiene información sobre la historia británica, el Reino Unido contemporáneo y asuntos prácticos como previsión sanitaria y bibliotecas públicas. ${ }^{76}$ Life in the United Kingdom se escribió sobre la base del informe del año 2003, The New and the Old, del grupo asesor «Life in the United Kingdom», dirigido por Bernard CRICK. ${ }^{77}$ Estrictamente hablando, esto pertenece a un primer ciclo de políticas, que también incluye la Ley de Nacionalidad,

${ }^{73}$ The Path to Citizenship, pág. 6. Para puntos de vista similares, véase el Libro Blanco Secure Borders, Safe Haven: Integration with Diversity in Modern Britain, London, Home Office, 2002, cap. 2; BRown y STRAw, The Governance of Britain, cit., Prólogo y cap. 4; Lord GoldSMITH, Citizenship: Our Common Bond, 2008, págs. 9-I2, II5-2I); y el Libro Verde Rights and Responsibilities: developing our constitutional framework, London, Ministry of Justice, 2009, Prólogo, cap. I y págs. 52-4.

${ }^{74}$ Este es también el punto de vista en Lord Goldsmith, Citizenship, cit., especialmente págs. 77-9.

${ }^{75}$ Home OfFICE, Official Citizenship Test Study Guide, London, TSO, 2008; Home Office, Passing the Life in the UK Test: Official Practice Questions and Answers, London, TSO, 2009; y Home OFFICE, Guide AN: Naturalisation as a British Citizen - A Guide for Applicants, London, Home Office, 2009.

${ }^{76}$ Home OfFICE, Life in the United Kingdom: A Journey to Citizenship, London, TSO, 2004; y HomE OFFICE, Life in the United Kingdom: A Journey to Citizenship, $2^{\text {a }}$ ed., London, TSO, 2007.

${ }^{77}$ Home OfFICE, The New and the Old, cit. 
Inmigración y Asilo de 2002. Un segundo ciclo consiste en el discurso de BROWN sobre la migración administrada y el Libro Verde The Path to Citizenship de 2008. ${ }^{78}$ Aunque las normas de inmigración son más estrictas en el segundo ciclo, no hay un cambio significativo en la forma en que se concibe la britanidad y en la forma en que se establece el límite en torno a la britanidad.

A continuación, me centraré en cómo la prueba de ciudadanía se caracteriza por la tensión constatativa/performativa identificada anteriormente, y cómo atender a esta tensión puede conducir a una crítica de la prueba, así como a una alternativa a la misma. Lo primero que hay que resaltar es cómo tanto Gordon BROWN como los materiales sobre la ciudadanía hacen hincapié en que la prueba y la ceremonia de ciudadanía significan la significancia, la importancia y el significado, de la ciudadanía y la naturalización. ${ }^{79}$ Se cree que la prueba y la ceremonia reflejan esta significancia, pero al mismo tiempo son necesarias para que la ciudadanía y la naturalización sean significantes, lo que implica que, hasta el momento, no han sido lo suficientemente significantes. Por lo tanto, la prueba y la ceremonia pretenden reproducir y producir la significancia de la ciudadanía británica.

La prueba de ciudadanía evalúa el conocimiento, específicamente el conocimiento sobre la vida en el Reino Unido. El conocimiento que los solicitantes deben tener para convertirse en ciudadanos británicos es práctico, histórico y cívico. En el informe The New and the Old, el grupo asesor escribe que, aunque el conocimiento histórico «puede fortalecer el compromiso con los valores comunes», el énfasis debe ponerse en las «fuentes de ayuda práctica e información relevante para la ciudadanía activa». ${ }^{80} \mathrm{El}$ conocimiento práctico incluye el conocimiento del idioma inglés, así como el conocimiento sobre cuestiones cotidianas, como quién puede actuar como árbitro para uno al rellenar una solicitud de empleo. El conocimiento histórico necesario es mínimo y se limita al conocimiento de las instituciones políticas (derechos de voto, por ejemplo) y la historia de la inmigración al Reino Unido. El conocimiento cívico incluye el conocimiento sobre instituciones políticas como el Parlamento y sobre derechos y deberes, por ejemplo, los derechos de voto.

El conocimiento cívico se enfatiza en The New and the Old y Life in the United Kingdom porque se dice que las instituciones y los valores cívicos son los que unen a los británicos. Las instituciones cívicas comunes y los valores crean un espacio multinacional y multicultural. El conocimiento y la integración en esas instituciones y valores no implica asimilación o que los ciudadanos británicos deban renunciar a sus identidades culturales y

\footnotetext{
${ }^{78}$ Home OfFICE, The Path to Citizenship: Next Steps in Reforming the Immigration System, London, Home Office, 2009; y Home OfFICE, The Path to Citizenship: Next Steps in Reforming the Immigration System: Government Response to Consultation, London, Home Office, 2009. Estos constituyeron la base para el Borders, Citizenship and Immigration Act 2009.

79 Brown, «Speech on Managed Migration and Earned Citizenship», cit.; Home Office, The New and the Old, cit., pág. 8; Home OfFICE, Official Citizenship Test Study Guide, cit., pág. 3; y HoME OFFICE, Naturalisation as a British Citizen, cit., pág. 3 .

${ }^{80}$ Home OfFICE, The New and the Old, cit., págs. I3 y I4. Aunque el primer capítulo de Life in the United Kingdom es una reseña histórica sobre la creación del Reino Unido, a los solicitantes no se les exige este conocimiento, excepto en lo que respecta a la historia de las instituciones políticas y la inmigración al Reino Unido.
} 
nacionales. ${ }^{8 \mathrm{r}}$ Las instituciones y los valores cívicos se describen de la siguiente manera en The New and the Old:

«Ser británicos nos parece que significa que respetamos las leyes, las estructuras parlamentarias y democráticas elegidas, los valores tradicionales de tolerancia mutua, el respeto por la igualdad de derechos y la preocupación mutua; y que le damos nuestra lealtad al estado (como comúnmente simboliza la Corona) a cambio de su protección. Ser británico es respetar esas instituciones, valores, creencias y tradiciones que nos unen a todos, las diferentes naciones y culturas, juntos en paz y en un orden legal» ${ }^{82}$.

Esta visión de la britanidad se refleja en Life in the United Kingdom y en los materiales sobre la prueba, y es muy similar a la visión que Gordon BROwN tiene acerca de la britanidad.

La prueba de ciudadanía claramente tiene una fuerte dimensión de constatación, ya que se supone que la prueba refleja el conocimiento del solicitante, y se supone que este conocimiento refleja con precisión lo que es (la vida en) el Reino Unido. Sin embargo, como argumenté anteriormente en el análisis del discurso sobre britanidad de BROwN, la dimensión performativa nunca está completamente ausente. Aquí consiste en decidir qué se trata del Reino Unido que deba probarse y qué es necesario para la obtención de la ciudadanía británica. Esto implica decisiones sobre qué es el Reino Unido y la britanidad, qué ciudadanía debería ser y qué es necesario para ello. El carácter normativo de estas decisiones se refleja en la introducción al primer capítulo en Life in the United Kingdom, que enfatiza la naturaleza controvertida de la historia: «Cualquier relato de la historia británica es ... una interpretación. Ninguna persona estaría de acuerdo con otra sobre qué incluir, qué omitir y cómo decirlo». ${ }^{83}$

Con respecto a la visión de la ciudadanía en la prueba de ciudadanía, Life in the United Kingdom contiene dos concepciones diferentes de ciudadanía y el conocimiento cívico necesario para convertirse en ciudadano británico. ${ }^{84}$ Primero, la visión de la ciudadanía que Bernard CRICK ha promovido en sus otros escritos, incluido el informe Education for Citizenship and the Teaching of Democracy in Schools que escribió para el grupo asesor sobre educación de la ciudadanía en las escuelas. ${ }^{85}$ Aquí el énfasis radica en la ciudadanía activa y la participación en las comunidades (especialmente las comunidades

${ }^{81}$ Ibid., págs. Iо y I2. Se afirma que las identidades son múltiples y fluidas. Ibid., pág. Io.

${ }^{82}$ Ibid., pág. II.

${ }^{83}$ Home OfFICE, Life in the United Kingdom, 2004, pág. I7. Igualmente, en la edición de 2007 en pág. 7. En una nota a la «Introducción» de la edición de 2004 (pág. 9 n. I), pero no en la de la edición de 2007, se afirma que Bernard CRICK escribió «las secciones inherentemente más interpretativas en The making of the United Kingdom y en How Britain is Governed», justamente los capítulos que abordan más explícitamente la identidad del Reino Unido y la naturaleza de la ciudadanía.

${ }^{84}$ Sobre esto, véase Patricia WHITE, «Immigrants into Citizens», The Political Quarterly, 79, 2008, págs. 22I-3I. Las diferencias son más notables en los capítulos I-4 en las dos ediciones de Life in the United Kingdom.

${ }^{85}$ Bernard CRICK, «Education for Citizenship: The Citizenship Order», Parliamentary Affairs 55, 2002, págs. 488-504; y «Qualifications and Curriculum Authority», Education for citizenship and the teaching of democracy in schools. Final report of the Advisory Group on Citizenship, 22 Septiembre 1998, London, QCA, I998, cap. 2 (también conocido como el «Crick Report»). 
étnicas o religiosas de los inmigrantes), y este enfoque se describe mejor como republicano cívico. En Life in the United Kingdom, este enfoque va de la mano de las opiniones de que las instituciones deben verse en su contexto histórico, que las instituciones existentes son imperfectas y que existen desacuerdos notables sobre la composición de las instituciones políticas. Esta opinión es la dominante en la edición de 2004 de Life in the United Kingdom. En la edición revisada de 2007 del libro, se pone menos énfasis en la imperfección de las instituciones existentes y en el desacuerdo, y la opinión del ciudadano es la de un ciudadano más pasivo que se porta bien y respeta la ley de la tierra.

Por lo tanto, las dos ediciones de Life in the United Kingdom presentan diferentes puntos de vista sobre la ciudadanía, y dado que la ciudadanía es lo que une a los británicos, son dos puntos de vista diferentes sobre la britanidad. La edición de 2004 parece preferible, con su peso relativamente mayor en la imperfección y los desacuerdos, lo que refleja la opinión de que lo que significa ser británico es una pregunta abierta. Puede ser que la visión de la ciudadanía defendida en la edición de 2007 sea simplemente el resultado de una actitud más decidida detrás del libro y el texto; la edición de 2007 es ciertamente mejor para enseñar sobre la prueba. Sin embargo, esto refleja una visión de la ciudadanía como decidida y de que los ciudadanos persiguen sus objetivos privados, en este caso, obtener un estatus legal específico.

Debería quedar claro que la prueba de ciudadanía considera la respuesta a la pregunta «qqué es la britanidad?» como dada. Dicho esto, la prueba y los materiales que la acompañan también tienen una dimensión normativa y performativa. En primer lugar, se encuentra la concepción de la ciudadanía más presente en la edición de 2004 de Life in the United Kingdom: ciudadanos que participan activamente en los debates sobre las instituciones políticas. Y, en segundo lugar, como ya he señalado, la prueba de ciudadanía se basa invariablemente en decisiones normativas sobre qué ciudadanía debería ser y qué es el Reino Unido. Si queremos incluir la pregunta «qqué es la britanidad?» en nuestra definición de britanidad e institucionalizar esto en la política, se puede argumentar que debemos enfatizar esta dimensión performativa a expensas de la dimensión constatativa de la prueba.

Sin embargo, hay una objeción importante a eso. Se puede objetar que sería imposible crear una prueba de ciudadanía que no considere la respuesta a la pregunta «¿qué significa ser británico?» como dada, y que esto sea así sin importar cuán «poco consistente» sea una concepción de britanidad que pueda ser la base de la prueba. En la prueba, se evalúa algo: el conocimiento, y sería imposible tener una prueba que no se basara en una clara distinción entre las respuestas correctas y las incorrectas, especialmente una prueba de tipo test. Este tipo de prueba tampoco puede evaluar valores o disposiciones del solicitante, y es, si no imposible, al menos muy difícil observar desacuerdos en dicha prueba.

Esto me parece correcto. En respuesta a este tipo de consideración, Patricia WHITE sugirió que, en lugar de la prueba de ciudadanía actual, los inmigrantes que soliciten la ciudadanía deberían cursar un programa de enseñanza similar al de la educación ciudadana para los escolares, donde se hace más hincapié en la participación, los valores y el 
compromiso crítico. ${ }^{86} \mathrm{El}$ informe The New and the Old, que formó la base de las nuevas reglas de naturalización, propuso que los solicitantes con las habilidades lingüísticas adecuadas pudieran realizar un curso corto de ciudadanía con una prueba al final. ${ }^{87}$ Sin embargo, esta propuesta no se implementó, y en su lugar estos solicitantes tuvieron que realizar el examen de ciudadanía.

¿Cuál podría haber sido el contenido de un curso de ciudadanía, con o sin una prueba final? Aquí uno podría mirar el informe Crick, la base para la introducción de la educación ciudadana en las escuelas. Este informe articula la necesidad de estudios de ciudadanía como respuesta a «niveles preocupantes de apatía, ignorancia y cinismo acerca de la vida pública», y aunque el informe no menciona explícitamente la britanidad, se refiere a la necesidad de «encontrar o restaurar un sentido de ciudadanía común, incluida una identidad nacional que sea lo suficientemente segura como para encontrar un lugar para la pluralidad de naciones, culturas, identidades étnicas y religiones que se encuentran desde hace tiempo en el Reino Unido». ${ }^{88}$ La enseñanza de la ciudadanía no solo debe ser la enseñanza del conocimiento, sino también debe enseñar a los alumnos las habilidades para convertirse en ciudadanos activos y críticos, según el informe. ${ }^{89}$ Este es exactamente el tipo de habilidades necesarias para una concepción de la britanidad centrada en la pregunta «¿qué es la britanidad?». Con el informe Diversity \& Citizenship, que revisó la educación para la ciudadanía en 2007, podemos desarrollar esto. El informe propone una nueva línea de educación para la ciudadanía centrada en la diversidad y la identidad, y asume las identidades como representativas, es decir, más construidas que esenciales o naturales. Como consecuencia, los alumnos deben «desarrollar una alfabetización crítica ... que les permita reflexionar sobre sus propias tradiciones culturales y las de los demás». ${ }^{\circ}$ Esto se aplica no solo a las identidades minoritarias, sino también a la «britanidad»: «El término «británico» significa diferentes cosas para diferentes personas», ${ }^{\text {,i }}$ y el informe enfatiza que las identidades y las normas dominantes también deben estar sujetas a una reflexión crítica. Esa reflexión crítica debe cuestionar las identidades heredadas de los alumnos y desarrollar un nuevo sentido de pertenencia, algo que se refleja en la pregunta que el informe sitúa en el centro de la enseñanza de la identidad y la diversidad: «¿quiénes creemos que somos?». ${ }^{92}$

Tal programa sería ciertamente preferible si queremos hacer de la pregunta «¿qué es la britanidad?» una parte de la britanidad y así incluirlo en lo que los nuevos ciudadanos británicos deben aprender para convertirse en (buenos) ciudadanos británicos. No escapamos al problema que tenemos que afrontar dado que tenemos una idea de lo que significa británico y britanidad, al menos si queremos juzgar quién puede, y quién no,

\footnotetext{
${ }^{86}$ WHITE, «Immigrants into Citizens», cit., pág. 229.

${ }^{87}$ The New and the Old, cit., págs. 22s.

${ }^{88}$ Education for citizenship and the teaching of democracy in schools, cit., págs. 8 y I7.

${ }^{89}$ Ibid., págs. 7 y ss., I3, 37, 56-9. Esto es para no olvidar los aspectos problemáticos del Informe, incluida la falta de atención al racismo institucional.

$9^{\circ}$ Diversity a Citizenship: Curriculum Review, London, Department for Education and Skills, 2007, pág. 24.

${ }^{91}$ Ibid., pág. 8.

${ }^{2}$ Ibid., págs. 13, 98-100.
} 
convertirse en ciudadano británico. No podemos evitar, en cierta medida, hacer valer algún contenido sobre la britanidad, por abstracto que sea este contenido. Esto es así incluso si queremos incluir dentro de nuestra definición de britanidad la pregunta «qqué es la britanidad?» En ese caso, todavía afirmamos que la britanidad «es» algo, incluso si también es cuestionado, colocando un signo de interrogación sobre su esencia, su «es». Del mismo modo, incluso si quisiéramos enfatizar la dimensión performativa del discurso sobre britanidad, -las formas en que nunca es simplemente un reflejo de cómo son las cosas, sino también una visión normativa de cómo deberían ser las cosas-, no hay un discurso que sea meramente constatativo. El discurso sobre britanidad no sólo debe basarse en los significados y definiciones existentes, incluso cuando se los critica, sino que un discurso puramente performativo sería un discurso completamente privado. Tal discurso no tendría fuerza porque carecería de cualquier vínculo con significados más o menos compartidos. Por esa razón, no es una cuestión ni constatativa ni performativa, sino de la relación entre estos dos aspectos del discurso. De manera similar, aunque incluir la pregunta «¿qué es la britanidad?» como parte de una definición de la britanidad disloca la britanidad (y también disloca esta definición de la britanidad), todavía estamos trabajando con un referente: la britanidad. Aunque ese referente no es extra-discursivo, el discurso sobre la britanidad no puede prescindir de este referente. De manera similar, incluso si nuestra definición de britanidad incluye la pregunta «¿qué es la britanidad?», todavía estamos trabajando con una visión particular de lo que es la britanidad, es decir, una identidad que se cuestiona. Sin embargo, estos problemas no deberían impedirnos tratar de institucionalizar la idea de britanidad con la pregunta «¿qué es la britanidad?», incluso si esto puede ser una empresa paradójica.

\section{Conclusión}

Al examinar el discurso de Gordon BROwN sobre britanidad, he identificado las tensiones entre identidad y diferencia, inclusión y exclusión y particularidad y universalidad. Sin embargo, estos no son específicos de la britanidad de BROWN, sino que son las tensiones generales que marcan cualquier discurso de identidad e inclusión. Aunque crítico con el discurso de BROWN, no pretendo oponerlo a un discurso de identidad inclusivo y no problemático, -como si eso fuera posible. También identifiqué una tensión entre descriptivo y normativo (y entre constatativo y performativo), y de ahí desarrollé la idea de que, fundamental para la britanidad, debería ser la pregunta «¿qué es la britanidad?» Y sugerí cómo podría institucionalizarse en el caso de las pruebas para la obtención de la ciudadanía, incluso si, como argumenté, es imposible evitar las tensiones identificadas aquí.

El resultado es que no hay identidad o inclusión sin exclusión, y no hay ciudadanía sin exclusión. Sin embargo, incluir la pregunta «¿qué es la britanidad?» en la britanidad es una forma de abordar esta exclusión. Es una forma de quitarle parte del poder de definición al estado y a la población mayoritaria. Es una forma de posicionar a los inmigrantes y no inmigrantes en un pie de más igualdad -pero sólo más. Esto es importante en el contexto de la historia británica, y no menos hoy en el contexto del Brexit. Por ejemplo, en los 
materiales de apoyo para las pruebas de ciudadanía (Life in the United Kingdom), los solicitantes de la ciudadanía británica se colocan en una línea de inmigrantes en el Reino Unido. Aunque esto destaca la forma en que la población británica existente es el resultado de la inmigración, aquí hay una distinción sutil entre tres grupos diferentes: los inmigrantes que quieren convertirse en ciudadanos británicos; aquellos ciudadanos británicos que eran inmigrantes o son descendientes de inmigrantes; y aquellos ciudadanos británicos que están clasificados como no inmigrantes. El grupo de no inmigrantes son descendientes de inmigrantes (romanos, normandos, etc.), pero esto nunca se conoce como inmigración y se coloca de forma segura en los tiempos premodernos. Por lo tanto, tenemos un grupo de no inmigrantes que conforman el país en el que los inmigrantes serán inmigrantes. Los (blancos) no inmigrantes se colocan en una posición de sujeto y los inmigrantes, ya sean antiguos o nuevos, en otra posición de sujeto. La relación de los no inmigrantes con Gran Bretaña no se problematiza, sino que se da: son británicos y no tuvieron que convertirse en británicos. Esto los posiciona en casa, al unísono con lo «británico», y por lo tanto capaces de vigilar las fronteras de lo británico. Aunque no es capaz de erradicar toda exclusión, desigualdad y poder, la pregunta «¿qué es la britanidad?» en el proceso de naturalización puede contribuir a limitar la exclusión, la desigualdad y el poder. 